\title{
COASTAL VULNERABILITY ASSESSMENT TO SEA LEVEL RISE INTEGRATED WITH ANALYTICAL HIERARCHY PROCESS
}

\author{
Dr. Gülizar Özyurt ${ }^{1}$, Prof. Dr. Ayşen Ergin ${ }^{1}$ and Cüneyt Baykal ${ }^{1}$
}

\begin{abstract}
This paper discusses a parameter based coastal vulnerability assessment model to sea level rise. The model integrates physical characteristics and human activities with expert perception through an application of analytical hierarchy process (AHP). The results of AHP enables users to assign weights to parameters of the model which determine vulnerability of a coastal area to the impacts of sea level rise such as coastal erosion, inundation, flooding due to storm surges, saltwater intrusion to groundwater and rivers. The results of AHP also indicates that sea level rise is not considered as one of the main driving forces of the impacts that might be already present contrary to the reports that state that sea level rise will trigger many problems along coastal areas. The application of the coastal vulnerability assessment model to two different coastal areas of Turkey showed that there is a need for overall evaluation of coastal areas in terms of vulnerability to sea level rise considering all the impacts. It is seen that assessing overall vulnerability is an important tool for national assessments. On the other hand, impact vulnerabilities are important when regional to local planning are considered since a region having a low overall vulnerability might show higher vulnerability for individual impacts. The proposed vulnerability methodology integrated with expert perception enables a simple yet effective representation of the coastal system while enabling decision makers to come up with proactive adaptation measures.
\end{abstract}

Keywords: coastal vulnerability, sea level rise, analytical hierarchy process

\section{INTRODUCTION}

There are a lot of challenges when management of coastal areas is considered. Demands of several stakeholders, conflicts on use of natural resources, management of densely populated areas, protection of ecosystem are just some of the challenges that the decision makers are faced with. Problems triggered by anthropogenic drivers are expected to be exacerbated considering the impacts of climate change. Sea level rise is an additional threat to the sustainability of the coastal system.

Expected impacts of sea level rise are; increased coastal erosion, inundation of lands, increased flooding of coastal areas due to increased storm surges and extended salt-water intrusion to fresh water resources. Coastal flooding in low lying areas is expected to cause major damage unless there is significant adaptation. Key human vulnerabilities to climate change and sea level rise exist mainly in deltas, low-lying coastal urban areas and small islands. Additionally, the process of sea level rise is expected to continue beyond 2100 for many centuries due to the substantial inertia inherited by sea level rise. (IPCC, 2007)

The long time-scale and the impacts being sensitive to sea level rise, socio-economic future and degree of adaptation puts the decision makers at cross roads when coastal zone management plans are prepared. On one side, there are the risks associated with climate change in the long term calling for adaptation measures. On the other hand, current society induced pressures to share the resources of coastal areas to strengthen the socio-economic development calling for immediate and sustainable actions complicate an already complex problem. Additionally, lack of reliable scientific knowledge, associated local data and manpower discourages the decision makers to consider sea level rise as an immediate threat that needs to be acted upon.

Several research initiatives were stated by Intergovernmental Panel on Climate Change, (IPCC, 2007) which strongly agrees with the understanding that limitations of available data, limitations of knowledge on especially interaction and integration of human and natural subsystems as well as limitations of integration of uncertainty by decision makers to actual policy making processes (adaptation options) as the key sources of problems that need to be overcome by the scientific approaches when coastal zones are considered.

The limitation on available data is especially an important problem for Turkey where long term coastal data, for most locations, does not exist. The quality of available data is another uncertainty due to many other factors such as the location of meteorological stations, calibration of the measuring devices and the duration of measurements including availability of human and budget capacity. Focusing on the limitation of data problem and underlining the fact that coastal areas are under threat due to many driving factors such as high urbanization rates and unsustainable use of available resources including the threat of climate change, a coastal vulnerability assessment model is developed (Ozyurt, 2007). The aim of the assessment model is to

- Compare different regions and rank them according to their vulnerabilities to sea level rise

\footnotetext{
${ }^{1}$ Coastal and Harbor Engineering Laboratory, Civil Engineering Dept, Middle East Technical University, Ankara, 06531, Turkey
} 
- Prioritize the impacts of sea level rise on the region according to the vulnerability of the region to each impact

- Determine which parameters are the most vulnerable parameters that need to be considered when planning for adaptation to sea level rise

by using governing parameters of the physical impacts triggered by sea level rise as indicators.

With the scope of this task a "Coastal Vulnerability Index to Sea Level Rise - CVI (SLR)" and the sub-indices of the impacts are defined in order to compare and prioritize the regions and the impacts on a common base.

\section{METHODOLOGY}

The developed method of coastal vulnerability assessment to sea level rise (Figure 1) using indicators for both physical and socioeconomic vulnerabilities analyses the following physical impacts of sea level rise on coastal areas;

- Increased coastal erosion

- Inundation

- Increased flooding due to increased storm surge

- Salinity intrusion to groundwater and estuaries

The model aims to determine the vulnerability of the region by defining the governing physical and human influence parameters of the physical impacts of sea level rise mentioned above using the available local data. To determine the indicators, the governing parameters that are believed to represent the physical processes of the impacts of sea-level rise were determined. Thieler and HammarKlose (2000) method for analyzing vulnerability of U.S. coasts was used as a baseline model however several other models were also considered to define each of these parameters, such as the Bruun rule for predicting coastal erosion and the Ghyben-Herzberg principle for salinity intrusion to groundwater resources. On the other hand, direct human activities in the coastal areas, such as settlement (land use that directly influences the evolution of coastal areas), as well as indirect activities, such as regulation of rivers by dams and reservoirs, were considered to determine the level of influence of anthropogenic actions. In light of these discussions, it was decided that 12 physical parameters and 7 human influence parameters would be appropriate without reducing the quality of the assessment. (Özyurt and Ergin, 2009)

\section{MODEL DEVELOPMENT FLOW CHART}

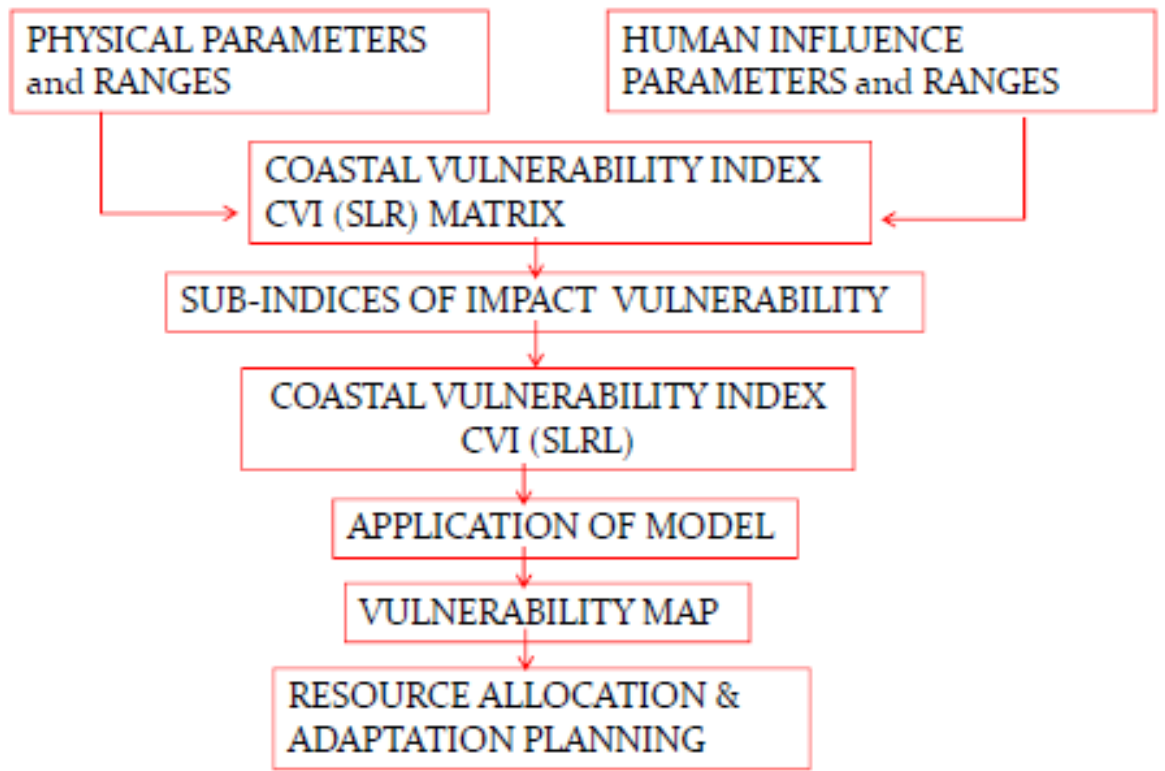

Figure 1. Coastal vulnerability assessment model flow chart

Vulnerability ranges determining the classes of each parameter according to the regional data were based on distribution of available data related to each parameter at locations around the world. Using regional data, each parameter is assigned a vulnerability rank of very low to very high vulnerability (1- 
5). For example, wave height parameter ranges from less than $0.5 \mathrm{~m}$ (very low vulnerability) to more than $8.0 \mathrm{~m}$ (very high vulnerability) around the world. The developed coastal vulnerability matrix (Figure 3), using vulnerability ranks of regional data, calculates the impact sub-indices and the overall vulnerability index applying the formulas presented below (Özyurt, 2007).

Physical impact sub-indices (CVIimpact) are the results of ratio of the sum of weighted parameters to the least vulnerable case result for the impact studied (Eq. 1). The calculated indices range between 1 and 5 indicating the level of vulnerability accordingly.

$$
C V I_{\text {impact }}=\frac{\left(\sum_{1}^{\mathrm{n}} \mathrm{PP}_{\mathrm{n}} * R_{n} * W_{n}\right)+\left(\sum_{1}^{\mathrm{m}} \mathrm{HP}_{\mathrm{m}} * R_{m} * W_{m}\right)}{\mathrm{CVI}_{\text {leastvulnerable }}}
$$

CVIimpact: Physical impact sub-index

$\mathrm{PP}_{\mathrm{n}}$ : Physical parameters

$\mathrm{HP}_{\mathrm{m}}$ : Human influence parameters

R: Rank of parameters

W: Weight of each parameter assigned by AHP

CVIleastvulnerable: Calculated least vulnerable case for a particular physical impact

Coastal Vulnerability Index (CVI (SLR)) is calculated according to the group the region is in which depends on the likelihood of the existence of the types of physical impacts (Eq. 2). The index is given as the ratio of the total value of parameter vulnerability ranks to the least vulnerability value of the corresponding group.

$$
C V I(S L R)_{n}=\frac{\sum \text { Parameters of Impacts of group }}{\sum \text { Least VulnerableCase of the group }}
$$

\section{Weight System of Model Parameters}

The objectives of the vulnerability assessment model require ranking of impacts and parameters relatively. The physical processes considered by the model are complex and continuous, thus different set of criteria and sub criteria must necessary be defined. Integration of human-induced parameters also increases this complexity. On the other hand, not all the parameters have equal influence on the physical process. In some cases, such as salt water intrusion to groundwater resources, one set of criteria (human parameters) are more dominant. To be able to derive accurate results using different sets of criteria requires assignment of weights to different parameters and criteria with respect to their influence on the impact vulnerability.

The Analytic Hierarchy Process (AHP) is a widely used multi-criteria decision making method aiming to derive relative priorities in multi-level hierarchic structures and to assign weights to these elements quantitatively. Based on pair-wise comparison of parameters by experts; AHP assigns weights to each parameter while eliminating the subjectivity of expert opinion as well as the inconsistency of the responses.

An online survey was prepared and sent to several experts from different countries (UK, Portugal, Australia, Turkey). The results were analyzed following the AHP procedure. The universal weights of each parameter were integrated within the model. It is possible to select and use other values as required by local characteristics or policy making structures however these universal weights are advised to be used for regional to national assessments.

It should be underlined that the results of AHP also illustrate the perception of experts regarding human-nature interaction and the threat posed by sea level rise. Clearly, human intervention to physical processes has more importance and is acknowledged as a more urgent threat than sea level rise (especially inundation, Table 1). Only on the longer term and with less importance, sea level rise is considered as a threat. Still, it is a factor to be considered when management of coastal areas is considered. 


\begin{tabular}{|l|l|}
\hline \multicolumn{2}{|c|}{$\begin{array}{c}\text { Table 1. Weights of individual impacts on coastal vulnerability } \\
\text { as perception of coastal experts }\end{array}$} \\
\hline Impacts & Weights \\
\hline Coastal Erosion & 0.36 \\
Inundation & 0.13 \\
Flooding due to Storm Surge & 0.18 \\
Salt water intrusion to Groundwater & 0.16 \\
Salt water intrusion to River/Estuary & 0.17 \\
\hline CR & 0.01 \\
\hline
\end{tabular}

\section{CASE STUDIES}

The developed coastal vulnerability assessment model is used to determine the vulnerability of Göksu Delta (Specially Protected Area), Mersin and Amasra; two very different coastal areas in Turkey (Figure 2). These different sites were selected to show the applicability of the coastal vulnerability model to different coastal areas.

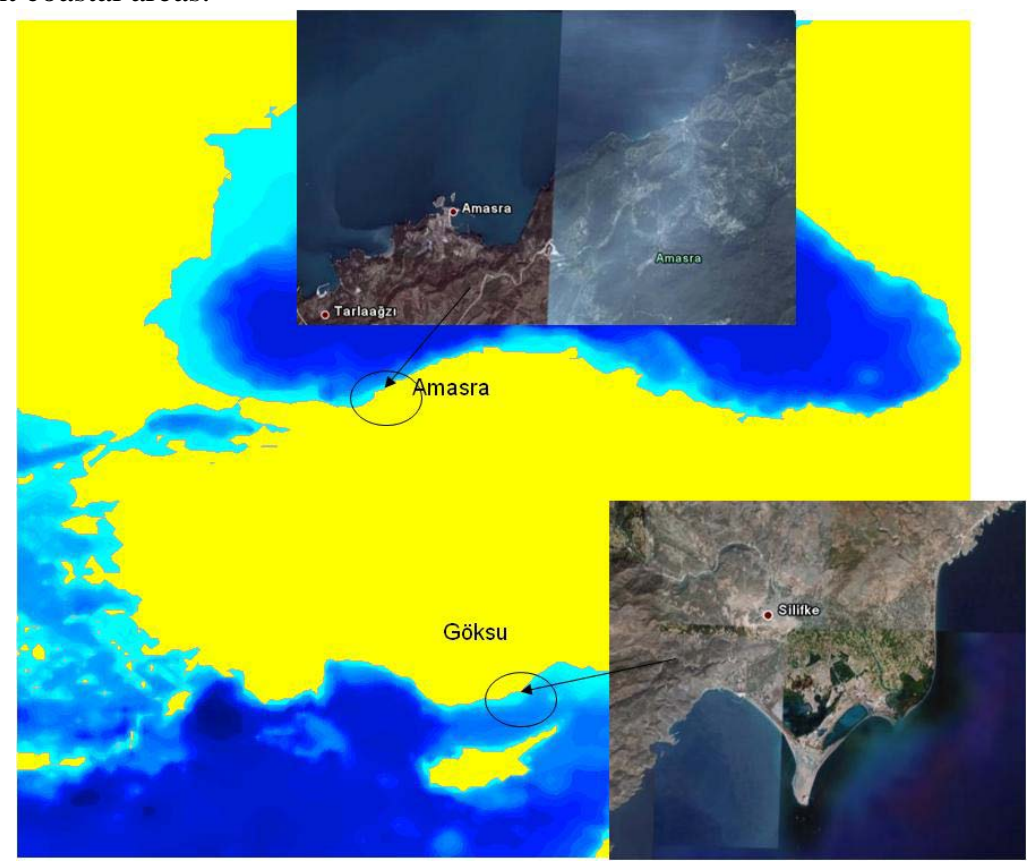

Figure 2. Case study sites: Goksu and Amasra

Goksu is a low-lying delta with lagoons and dunes hosting very high human activity both socially and economically. The delta is one of the most productive agricultural areas. Additionally the delta has a specially protected area status due to wetlands and the unique ecosystem. Additionally, Goksu River is a regulated river where additional regulation structures are continued to be built at the present. Groundwater is another important resource which is highly demanded due to the agricultural activity.

On the other hand, Amasra situated on Black Sea coast, shows a very different geomorphology including high cliffs and narrow pocket beaches accompanied by a harsh wave climate (wave height of 8 meters with return periods 100 years). The small town has a commercial port and several small fisheries while there is very low agricultural or land related activity. Most of the human activity is derived by small scale tourism and mining.

Available local data is used to calculate impact and vulnerability scores of both regions using the vulnerability index matrix integrating the AHP study results as universal weights. An example of the vulnerability index matrix for Amasra is given in Figure 3. 


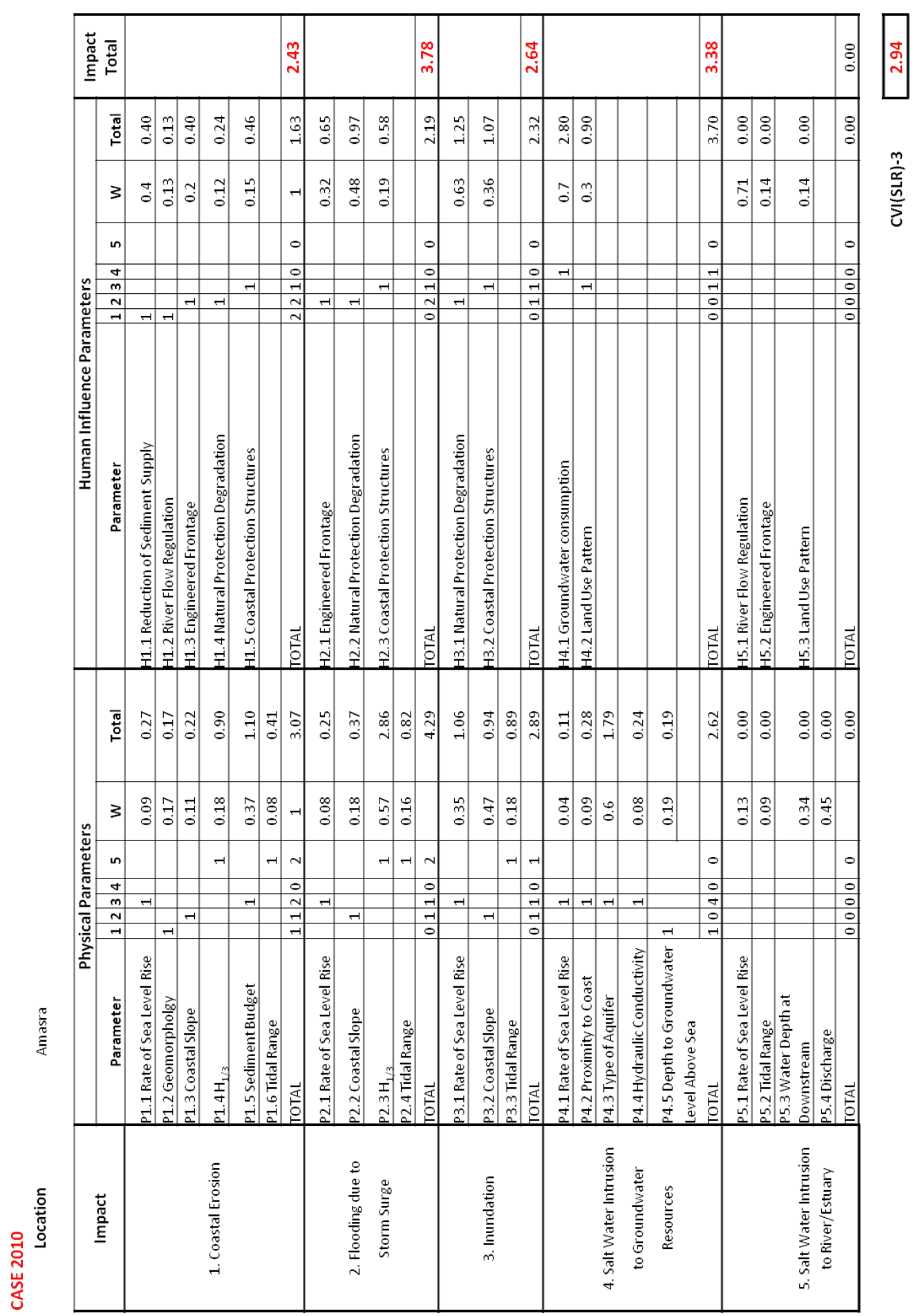


COASTAL ENGINEERING 2010

\begin{tabular}{|l|c|c|}
\hline \multicolumn{2}{|c|}{ Table 2. Results of coastal vulnerability assessment model for Amasra and Goksu } \\
\hline \multicolumn{2}{|c|}{ Regions } \\
\hline Coastal Erosion & Amasra & Goksu \\
\hline Flooding due to Storm Surge & 2.43 & 3.82 \\
\hline Inundation & 3.78 & 4.15 \\
\hline Saltwater Intrusion to Groundwater & 2.64 & 4.37 \\
\hline Saltwater Intrusion to Rivers/Estuary & 3.38 & 3.8 \\
\hline & & 3.15 \\
\hline VULNERABILITY & - & 3.83 \\
\hline
\end{tabular}

The results of the vulnerability assessment for both regions are presented in Table 2 respectively. The results show that Amasra has low vulnerability in general (2.94/5) compared to Goksu which has high vulnerability (3.83/5). The results indicate that when national scale assessment is considered, priority for implementing adaptation measures should be given to Goksu. This result is also compatible with results presented in IPCC, 2007 which state that coastal deltas are hotspots of key human vulnerabilities.

Impact scores of both regions enable forming a framework for adaptation measures for specific impacts. National to regional management plans could consider these scores as baseline or initiation point for adaptation studies. Analysis of the impact scores (Table 2) generate the following results:

- Goksu is expected to sustain damage due to inundation in long term and coastal flooding due to storm surges in short term.

- Coastal erosion and sustainability of groundwater resources are additional vulnerabilities that would have significant impact on the overall sustainability of Goksu region.

- Significant impact of coastal flooding in Amasra is highlighted by high vulnerability score (3.78/5) which also exceeds the overall vulnerability score (2.94).

- $\quad$ Long term processes due to sea level rise are not expected to create major disturbance in Amasra if minor revisions are integrated to overall adaptation planning.

Another output of the coastal vulnerability assessment model is histograms of regions comparing physical characteristics and human activities with respect to individual impacts of sea level rise. When Figure 4 and 5 is analyzed, these histograms can act as guidelines for local specific zone management and adaptation planning. Histogram encourages the decision makers to select the most effective solution available or to develop a set of alternative solutions for a specific impact. For example, histogram of Goksu shows that human influence on groundwater resources is much more dominant when the vulnerability of groundwater is considered. Although the physical characteristics of groundwater resource of the region shows low vulnerability, high agricultural activity and high demand on water increases the overall vulnerability significantly. This result calls for a policy driven adaptation measures which should ensure the proper and regulated use of groundwater resources through monitoring of wells, use of different agricultural landscape, etc. On the other hand, when histogram of Amasra is analyzed, it is seen that the physical characteristics of the region increases the vulnerability of the coastline against flooding, inundation and erosion. This result calls for structural adaptation measures if the area needs to be protected such as building dikes or proactive land use planning such as managed retreat. Again demand of water contributes to the vulnerability of groundwater resources of this region as well. 


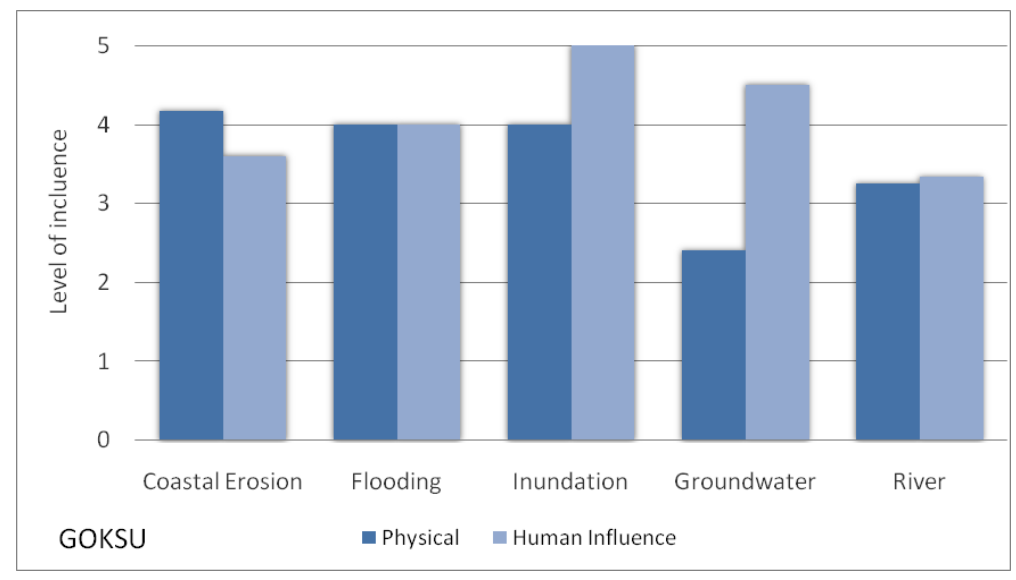

Figure 4. Influence histogram for Goksu

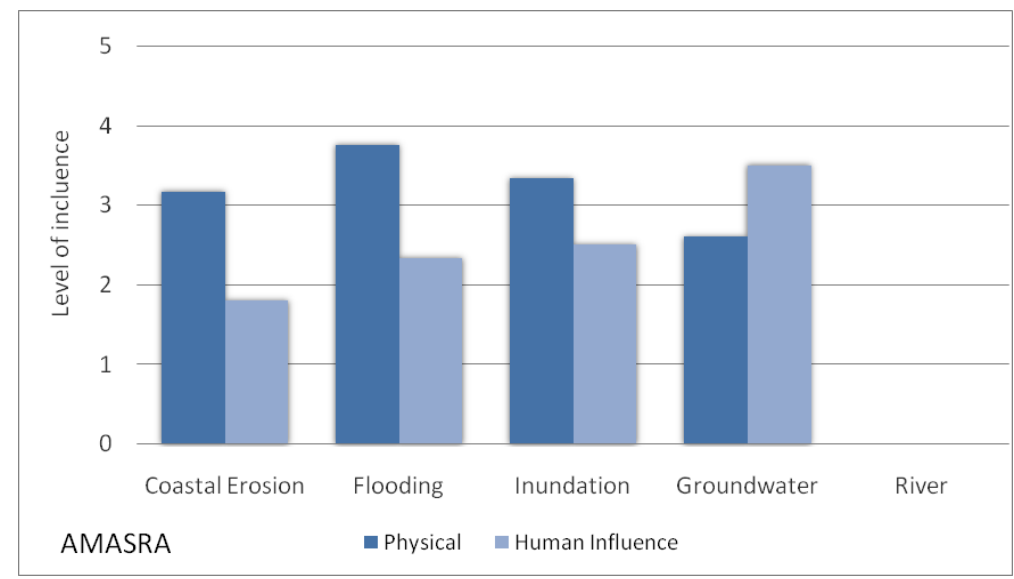

Figure 5. Influence histogram for Amasra

\section{CONCLUSION}

A parameter based coastal vulnerability assessment model (Ozyurt, 2007) was upgraded by assigning weights to each parameter of the model. It is important to assign weights to each parameter to model the system more accurately. Assignment of weights to physical and human groups by integrating expert opinions using analytical hierarchy process eliminated the discrepancy of subjective evaluations of the users. At the same time, inclusion of opinions enabled the integration of stakeholder views to the coastal vulnerability model.

The perception of experts were also analyzed with the help of the survey results and the analytical hierarchy process which underlined the fact that the coastal experts do not consider the sea level rise as one of the governing parameters when the physical impacts are considered. Also it is seen that human activities are determined to be the governing parameters especially when use of freshwater resources are considered rather than the physical characteristics of the coastal region. This strengthens the view of IPCC (2007) that integrated impact and vulnerability assessment methods combining natural and human systems should be one of the key research priorities.

The study also underlines the fact that there is the necessity for an overall evaluation of the coastlines not just hotspots (e.g. deltas). Coastal areas might show different levels of vulnerability to different impacts of sea level rise and an overall evaluation would highlight these differences. Also the overall evaluation of coastal vulnerability enables larger zone management practices. The applicability and the sensitivity of the proposed coastal vulnerability assessment model to local conditions were presented by analyzing the results of two different coastal areas of Turkey. The results satisfy the general literature when the physical characteristics of both case study regions are considered.

Implementation of the model with fuzzy decision making systems is the next step to include the uncertainty concept related to vulnerability of coastal areas and the sea level rise. This step will further ensure that the applicability of the model to different coastal regions with different resolutions of data would satisfy minimum uncertainty. This would enable the decision makers to generate and implement adaptation measures proactively. 
Also, integration of the model to geographical information systems leads to generation of maps that could both act as public awareness material and an important base study for other research related to coastal zone management such as social vulnerability.

\section{ACKNOWLEDGMENTS}

The writers would like to acknowledge that this study was partially supported by the TUBITAK Research Grant No: 108M589, "Kıyılarda İklim Değişikliğine Karşı Kumlanma Modeli Destekli Kırılganlık Analizi Projesi - KIDEKA" (Coastal vulnerability assessment model coupled with sediment transport model).

\section{REFERENCES}

Cheng, E.W.L. and Li, H., 2001. Analytic hierarchy process: An approach to determine measures for business performance. Measuring Business Excellence, 5(3): 30-36.

Harvey, N., Clouston, B. and Carvalho, P., 1999. Improving Coastal Vulnerability Assessment Methodologies for Integrated Coastal Zone Management: an Approach from South Australia. Australian Geographical Studies, 37(1): 50-69.

Intergovernmental Panel on Climate Change Staff, 2007. Fourth Assessment Report - Climate Change 2007: Mitigation, Vulnerability and Adaptation. Contribution of Working Group II to the fourth assessment report of the Intergovernmental Panel on Climate Change (IPCC). Cambridge University Press, Cambridge.

Kuruüzüm, A. and Atsan, N., 2001. Analitik hiyerarşi yöntemi ve işletmecilik alanindaki uygulamalari (the analytic hierarchy process approach and its applications in business). Akdeniz İ.I.B.F. Dergisi (1): 83-105.

Özyurt, G., 2007. Vulnerability of Coastal Areas to Sea Level Rise: A Case Study on Göksu Delta. Ankara, Turkey: Middle East Technical University, Master’s thesis, 99p.

Özyurt, G. and Ergin, A., 2010. Improving coastal vulnerability assessments to sea-level rise: a new indicator based methodology for decision makers. Journal of Coastal Research. March 2010 West Palm Beach (Florida), ISSN0749-0208.

Ozyurt, G., 2010. Fuzzy Vulnerability Assessment of Coastal Areas to Sea Level Rise. Ankara, Turkey: Middle East Technical University, PhD thesis, 300p.

Saaty, L.T., 1980. The Analytic Hierarchy Process. McGraw-Hill Comp., U.S.A.

Saaty, T.L., 1994. How To Make A Decision: The Analytic Hierarchy Process. Interfaces, 24(6): 1943.

Small C and Nicholls R J (2003) A Global Analysis of Human Settlement in Coastal Zones. Journal of Coastal Research 19: 584-599

Thieler, E.R. and Hammar-Klose, E.S., 2000. National Assessment of Coastal Vulnerability to Future Sea-Level Rise: Preliminary Results for the U.S. Atlantic Coast. U.S. Geological Survey, Open File Report, pp. 99-593. 